\title{
The long-term effects of anti-retroviral protease inhibitors on sugar transport in $\mathbf{L 6}$ cells
}

\author{
R J Germinario ${ }^{1,2,3,4}$, S P Colby-Germinario ${ }^{1}$, C Cammalleri ${ }^{1,2}$ \\ and $\mathbf{M} \mathbf{A}$ Wainberg ${ }^{1,3,4}$ \\ ${ }^{1}$ Lady Davis Institute for Medical Research, SMBD Jewish General Hospital, 3755 Cote St Catherine Road, Montreal, Quebec, Canada \\ ${ }^{2}$ Concordia University, Department of Biology, Montreal, Quebec, Canada \\ ${ }^{3}$ McGill AIDS Center, Montreal, Quebec, Canada \\ ${ }^{4}$ McGill University Department of Medicine, Montreal, Quebec, Canada \\ (Requests for offprints should be addressed to R J Germinario, McGill AIDS Center, Lady Davis Institute for Medical Research, 3755 Cote St Catherine Road, \\ Montreal, Quebec, Canada H3T 1E2; Email: ralph.germinario@mcgill.ca)
}

\begin{abstract}
The objective of this study was to investigate the longterm effects of anti-retroviral protease inhibitors (PIs) on 2-deoxy-D-glucose (2-DG) transport in L6 cells in vitro. Exposure of L6 cells to saquinavir, ritonavir, indinavir and amprenavir resulted in significant increases in 2-DG transport using PI concentrations of $1-10 \mu \mathrm{M}$ with continual exposure to PI. After removal of the PI for up to $48 \mathrm{~h}, 2-\mathrm{DG}$ transport increases did not change and remained at pre-reversal levels. These changes in 2-DG transport were not related to stress-induced sugar transport or to apoptosis. The examination of glucose transporter (GLUT) 1, 3 or 4 translocation with subcellular fractionation indicated that insulin (i.e. $67 \mathrm{nM}$ ) could induce the
\end{abstract}

translocation of all the GLUTs to the plasma membrane. Also, ritonavir $(10 \mu \mathrm{M})$, which leads to a 2 -fold increase in 2-DG transport, demonstrated increased GLUT (i.e. 1, 3 or 4) presence in the plasma membrane fraction, in the presence or absence of insulin. This increased 2-DG transport involved transporter presence in plasma membrane preparations and did not affect the ability of insulin to stimulate 2-DG transport with continual PI exposure. The mechanism(s) involved indicates ready reversibility of PI effects on transporters. The mechanism(s) why reversibility of PI-induced 2-DG transport was similar plus or minus PI was not apparent.

Journal of Endocrinology (2003) 178, 449-456

\section{Introduction}

Protease inhibitors (PIs) exhibit antiviral activity in both primary lymphoid, monocyte cell lines and against a variety of viral strains including clinical isolates with zidovudine resistance (Martin et al. 1995, Winslow \& Otto 1995). The PIs are active as administered and affect HIV replication in acute as well as chronically infected cells (Gao et al. 1993). Further, the employment of combinations of PI with one or more nucleoside reverse transcriptase inhibitors has proven most effective in treating AIDS patients and maintaining low viral loads (Flexner 1998). While this combined anti-retroviral therapy (i.e. highly active anti-retroviral therapy or HAART) has represented a significant advance in the treatments of HIV infection, side-effects of different degrees of severity have been reported such as fat wasting, insulin resistance, central adiposity, hypertriglyceridemia and hyperglycemia (Hammer et al. 1997, Mouton et al. 1997, Carr et al. 1998, 2000, Lo et al. 1998, Virabin \& Aquilina 1998, Gervasoni et al. 1999, Mulligan et al. 2000). Further, the removal of these drugs can reverse the metabolic disturbances; how- ever, such an action results in a dramatic reappearance of circulating virus in the bloodstream after up to 2 years of combination drug treatment. Thus, the patient must remain on drug therapy.

Significantly, the cause(s) of these side-effects are unknown but they exhibit a remarkable similarity to the characteristics of metabolic syndrome X (Reaven 1993). Of considerable interest is that all of these changes have been shown to be associated with an increased risk of cardiovascular disease or diabetes (Reaven 1999). Insulin resistance appears to be a major player in the lipodystrophic effects seen in HAART patients. Recent reports have indicated that PIs can decrease the intrinsic activity of the glucose transporter 4 (GLUT 4) (Murata et al. 2000) and cause insulin resistance after short-term PI exposure (Nolte et al. 2001, Hruz et al. 2002) in rat muscle. In the latter two studies, transient insulin resistance was found to be induced by PIs. It was suggested that this modulation of GLUT 4 may relate to the insulin resistance observed with HAART AIDS patients.

In the study described herein, we have investigated the long-term effects of PI on basal and insulin-stimulated 
sugar transport in L6 cells (i.e. a representative culture system of muscle). This study was undertaken to further characterize the mechanism(s) involved in the modulation of 2-DG transport by PIs in a tissue known for $~ 90 \%$ insulin-stimulated glucose disposal (DeFronzo et al. 1981, Baron et al. 1994).

\section{Materials and Methods}

\section{L6 myoblasts}

Myoblasts were grown in Dulbecco's minimum essential medium (DMEM) containing 10\% (v/v) fetal bovine serum (FBS) (Germinario et al. 1978, Bilan et al. 1992). The cells were grown at $37^{\circ} \mathrm{C}$ in an atmosphere of $5 \%$ $\mathrm{CO}_{2} / 95 \%$ air. Cells were harvested from appropriate culture vessels after incubation for $5 \mathrm{~min}$ with $0.02 \%$ (w/v) EDTA and 1-2 min with $0.06 \%$ (w/v) trypsin (Difco Laboratories, Oakville, Ontario, Canada) at room temperature. When the monolayers became confluent, the $10 \%$ FBS-DMEM was removed and replaced with an equal volume of fusion medium ( $\alpha$-MEM containing $2 \%$ FBS (v/v). All experiments were done 4-5 days later when $>85 \%$ of the control cells were differentiated as assessed visually through morphological changes. Both 10\% FBS-DMEM and 2\% $\alpha$-MEM were supplemented with a $100 \times$ penicillin/streptomycin antibiotic solution. L6 cells were subcultured every 3 days at about 75\% confluence using a split ratio of $1: 3$ or more.

\section{Insulin-stimulation protocol}

Generally, the monolayers of cells were serum deprived for $18 \mathrm{~h}$ in serum-free DMEM with $1 \mathrm{mg} / \mathrm{ml}$ BSA $(0 \%$ DMEM). L6 cells were grown to the appropriate stage of differentiation and serum deprived. To determine sugar transport, 2-deoxy-D- $\left[{ }^{3} \mathrm{H}\right]$ glucose $(2-\mathrm{DG})$ was employed at a concentration of $0.05 \mathrm{mM}$ (specific activity $0.023 \mu \mathrm{Ci} / \mathrm{nmol}$ ) and 2-DG uptake at linear and ratelimiting conditions were employed as described previously (Germinario et al. 1978, 1989, 1993, Bilan et al. 1992, Pratt et al. 1994, Pratt \& Germinario 1994, Tao et al. 1995).

\section{Sugar transport procedures}

Details of the experimental protocol employed can be found elsewhere (Germinario et al. 1978, 1989, 1993, Pratt \& Germinario 1994, Pratt et al. 1994, Tao et al. 1995). Briefly, cells were plated at $10^{4}$ cells $/ \mathrm{cm}^{2}$ on plastic Petri dishes (35 mm diameter; Falcon, Oakville, Ontario, Canada) and grown as described. The cell monolayers were rinsed once in $0 \%$ MEM and incubated for $1 \mathrm{~h}$ with insulin. Hexose transport was assessed by measuring the uptake of 2-DG in PBS (pH 7.4) containing 0.05 mM
2-DG at $37^{\circ} \mathrm{C}$. There was no PI present in any uptake medium. The radioactive medium was removed and the monolayers were rinsed four times with $4{ }^{\circ} \mathrm{C}$ PBS. Since the PIs were dissolved in a dilute solution of DMSO, additional controls were employed to determine the effects of DMSO on 2-DG transport. No differences were seen between 2-DG transport with or without DMSO up to a concentration of $0.5 \%$ DMSO. The 2-DG transport in the DMSO test group exhibited an average of $102 \cdot 8 \pm 4 \%$ of the 2-DG transport in the non-DMSO group (paired $t$-test, $P>0 \cdot 05)(n=24)$. All control groups are DMSOcontaining controls. Further, the use of $10 \mu \mathrm{M}$ cytochalasin B, a specific inhibitor of carrier-mediated sugar transport, indicated that the increases seen in 2-DG transport were carrier-mediated as the 2-DG transport for all groups employed remained $\sim 15 \%$ of the total $2-\mathrm{DG}$ transport in the presence of $10 \mu \mathrm{M}$ cytochalasin B (data not shown). The cell monolayers were dissolved in $1 \mathrm{M}$ $\mathrm{NaOH}$ and aliquots were taken for liquid scintillation counting and protein determination (Lowry et al. 1951).

\section{Cell fractionation and membrane isolation}

L6 cells from $100 \mathrm{~mm}$ diameter Petri plates (Falcon) were treated and plasma membranes prepared and isolated as previously described (Tao et al. 1995). In short, after homogenization with a Dounce homogenizer, a $1000 \mathrm{~g}$ centrifugation to remove unbroken cells and nuclei was done. This was followed by a $27000 \mathrm{~g}$ centrifugation yielding the crude membrane pellet from one to three plates which exhibited a 3-fold enrichment of ouabainsensitive $\mathrm{Na}^{+} / \mathrm{K}^{+}$ATPase vs the cell homogenate (data not shown).

\section{Western analysis procedure}

Whole-cell monolayers or membrane fractions were suspended in $0.5 \mathrm{ml}$ PBS with a proteinase inhibitor (phenylmethylsulfonyl fluoride) at a final concentration of $1 \mathrm{mM}$. Prior to electrophoresis samples were solubilized in 2\% SDS (Pierce Chemical Co., Rockford, IL, USA), 10\% glycerol, $1 \mathrm{mM}$ EDTA, 0.002\% bromophenol blue, 100 mM Tris-HC1 (pH 6.8) (Germinario et al. 1993). Electrophoresis was performed as described previously (Germinario et al. 1993, Pratt \& Germinario 1994, Pratt et al. 1994). All lanes contained $40 \mu \mathrm{g} / \mathrm{lane}$ of cell protein. Purified erythrocyte GLUT was prepared as described elsewhere (Baldwin et al. 1982). A rabbit polyclonal antibody to the erythrocyte GLUT 1 was prepared using the purified transporter obtained from the preceding procedure. This antibody has been characterized as to its reactivity to the GLUT 1 (Germinario et al. 1978, 1993, Pratt \& Germinario 1994, Pratt et al. 1994, Tao et al. 1995). Additionally, membranes were probed with a rabbit anti-mouse GLUT 3 (Alpha Research Diagnostics, San Antonio, TX, USA) or GLUT 4 


\section{A.Effect of Saquinavir on Basal 2-DG Transport}

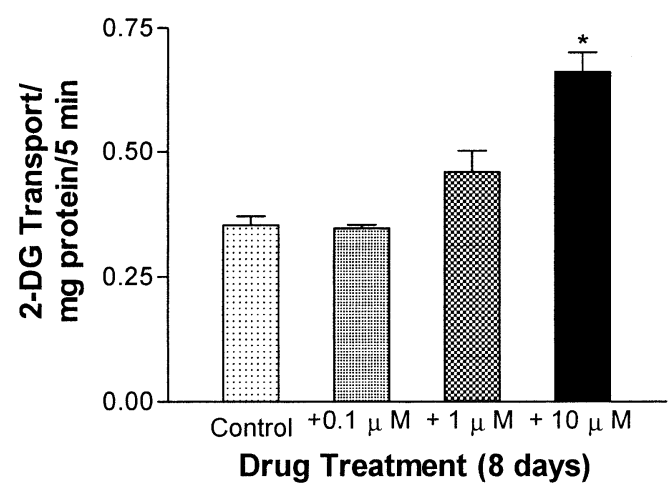

B.The Effect of Indinavir on Basal 2-DG Transport

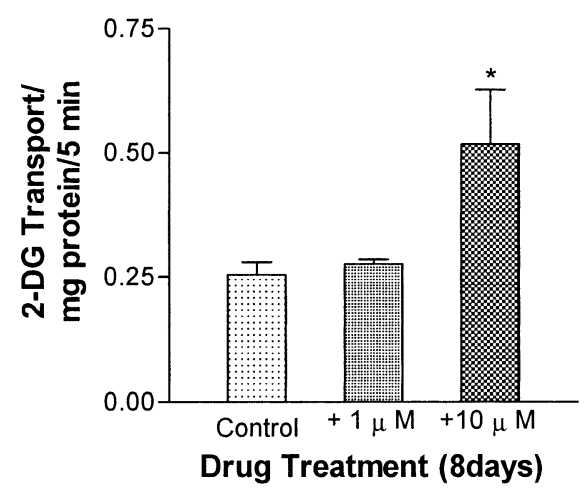

C.The Effect of Ritonavir on Basal 2-DG Transport

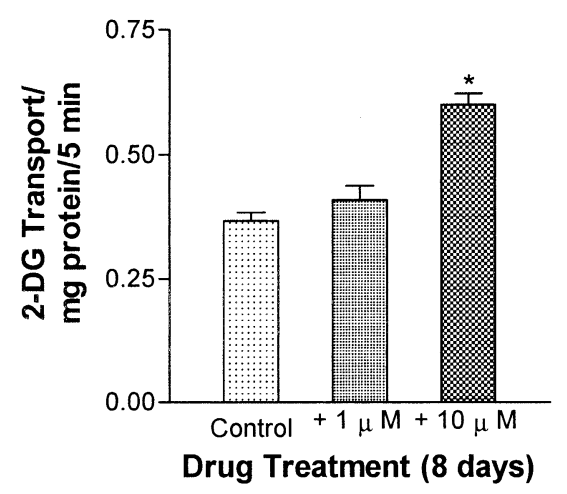

antibody. Briefly, Western blot analysis was carried out as follows: (i) samples were solubilized in Laemmli buffer (Laemmli 1970) and electrophoresis was performed on $10 \%$ polyacrylamide slab gels under non-reducing conditions (Andrejchyshyn et al. 1991, Germinario et al. 1993, Pratt \& Germinario 1994, Pratt et al. 1994, Tao et al. 1995); (ii) proteins were blotted onto nitrocellulose paper that was blocked with 3\% BSA in PBS $/ 0.5 \%$ Tween 20 $\left(1 \mathrm{~h}\right.$ at $\left.20^{\circ} \mathrm{C}\right)$; (iii) this was followed by incubation with specific antibody overnight at $4{ }^{\circ} \mathrm{C}$; and (iv) detection of GLUT 1, 3 or 4 was performed by enhanced chemiluminescence (ECL kit; Amersham Life Sciences) using horseradish-peroxidase anti-rabbit as a secondary antibody for $1 \mathrm{~h}$ at $20^{\circ} \mathrm{C}$. The blot was exposed to XAR film (Eastman Kodak, Rochester, NY, USA). The film was scanned and analyzed using UN SCAN IT gel software (Silk Science, Orem, UT, USA).

\section{Materials}

Tritium-labeled 2-DG was purchased from ICN Radiochemical Division (Irvine, CA, USA). 2-DG was purchased from Calbiochem (La Jolla, CA, USA); BSA from Nutritional Biochemicals (Walnut, CA, USA) and phenylmethylsulfonyl fluoride from Sigma. Our thanks go to Hoffman LaRoche for the gift of the PI saquinavir, to Merck for indinavir, to Abbott Pharmaceuticals for ritonavir and to Glaxo Wellcome Inc. for amprenavir.

\section{Statistics}

The level of significance chosen for any analysis employed herein was $5 \%$. The tests employed were one-way ANOVAs or two-tailed paired $t$-tests. All data are \pm S.E.M.

\section{Results}

We studied the effects of various PIs in L6 cells on 2-DG transport over a range of PI concentrations (Fig. 1A-C). In Fig. 1A, the data showed an increase in 2-DG transport by saquinavir over the range $1-10 \mu \mathrm{M}$. The transport increases were $>2$-fold at all PI concentrations $(P<0 \cdot 05$, one-way ANOVA, $n=3$ ). In Fig. 1B, the indinavirinduced increases seen in 2-DG transport were significantly higher at $10 \mu \mathrm{M}(P<0 \cdot 05$, one-way ANOVA, $n=3$ ). The difference was on average $1 \cdot 8$-fold greater at

Figure 1 The effect of increasing concentrations of saquinavir, indinavir and ritonavir on basal 2-DG transport in L6 cells. Details as in Materials and Methods. (A) Saquinavir, one-way ANOVA, ${ }^{\star} P<0 \cdot 05, n=3$; triplicate plates in all experiments. Data \pm S.E.M. (B) Indinavir, one-way ANOVA, ${ }^{*} P<0 \cdot 05, n=3$; triplicate plates in all experiments. Data \pm S.E.M. (C) Ritonavir, one-way ANOVA, ${ }^{*} P<0.05 ; n=3$; triplicate determinations in all experiments. Data \pm S.E.M. 
Table 1 The transport of 2-DG after removal of Pls from the L6 cells for 24 and $48 \mathrm{~h}$. All data \pm S.E.M.

\begin{tabular}{|c|c|c|c|}
\hline & \multirow{2}{*}{$\begin{array}{l}\text { 2-DG transport } \\
(\text { nmole/mg } \\
\text { protein } / 5 \mathrm{~min})\end{array}$} & \multicolumn{2}{|c|}{$\begin{array}{l}\text { 2-DG transport } \\
\text { ratio after reversal }^{\text {b }}\end{array}$} \\
\hline & & $24 \mathrm{~h}^{\mathrm{d}}$ & $48 \mathrm{~h}^{\mathrm{e}}$ \\
\hline \multicolumn{4}{|l|}{ Treatment $^{a}$} \\
\hline Control & $0 \cdot 217 \pm 0 \cdot 02$ & $1 \cdot 06 \pm 0 \cdot 03$ & $1 \cdot 05 \pm 0 \cdot 01$ \\
\hline Ritonavir $(10 \mu \mathrm{M})$ & $0 \cdot 334 \pm 0.04^{c}$ & $0.97 \pm 0.07$ & $1 \cdot 12 \pm 0 \cdot 09$ \\
\hline Indinavir $(10 \mu \mathrm{M})$ & $0 \cdot 281 \pm 0 \cdot 01^{c}$ & $0.98 \pm 0.05$ & $1 \cdot 11 \pm 0 \cdot 05$ \\
\hline Saquinavir $(10 \mu \mathrm{M})$ & $0 \cdot 36 \pm 0 \cdot 01^{c}$ & $0.92 \pm 0.05$ & N.D. \\
\hline
\end{tabular}

Treatment with drugs was at plating (3-4 days) and during 4 days of induction.

${ }^{b}$ Reversal represents time after removal of drugs. Control represents 2-DG transport during reversal time. The ratios represent 2-DG transport in reversed divided by the drug-exposed control.

'The drug-treated groups are all significantly elevated (one-way ANOVA, $P<0 \cdot 05, n=3)$.

${ }^{\mathrm{d}}$ No significant difference between $24 \mathrm{~h}$ reversed groups (one-way ANOVA, $P<0 \cdot 05, n=3$ )

${ }^{\mathrm{e}}$ No significant differences between $48 \mathrm{~h}$ reversed groups (one-way ANOVA, $P<0 \cdot 05, n=3)$.

All other methods are as described previously.

the highest concentration tested. For ritonavir, similar results were obtained (Fig. 1C) as seen for $10 \mu \mathrm{M}$ ritonavir, the increase seen being 1.6-fold vs control. Again the difference was significantly different for the ritonavir group $(P<0 \cdot 05$, one-way ANOVA, $n=3$ triplicate determinations on all experiments).

The increases in 2-DG transport seen in L6 cells after PI exposure were not readily reversible. The data in Table 1 clearly show that a variety of PIs increase 2-DG transport from 1.3- to 1.7-fold. After removal of PIs for $24 \mathrm{~h}$, the 2-DG transport remained the same as seen in the PIexposed or reversed group (Table 1). Saquinavir, ritonavir or indinavir, once removed, i.e. for $24 \mathrm{~h}$, resulted in 2-DG transport ratios + PI to $-\mathrm{PI}$ of $0 \cdot 92 \pm 0 \cdot 05$ to $0 \cdot 98 \pm 0 \cdot 05$ for the PI-exposed groups. Forty-eight hours after the removal of PI, the transport elevations in the PI reversed groups were not affected (Table 1).

Others have observed that transport changes were associated with exposure to PI in 3T3 L1 adipocytes (Murata et al. 2000). The changes reported were significantly decreased 2-DG transport in insulin-stimulated 3T3-L1 adipocytes (Murata et al. 2000). These studies are not comparable with those reported herein as exposure to PI was for 6 min to $4 \mathrm{~h}$ at $100 \mu \mathrm{M}$ PI (Murata et al. 2000). We have looked at the effects of continual exposure (i.e. during induction of differentiation) to $10 \mu \mathrm{M}$ indinavir,
Table 2 Effects of insulin on Pl-exposed L6 cells 2-DG transport (nmole 2-DG/mg protein/5 min). L6 myoblasts were induced to differentiate as described in Materials and Methods. Saquinavir, indinavir, ritonavir and amprenavir were present throughout. Saquinavir, indinavir, ritonavir and amprenavir represent $10 \mu \mathrm{M}$ of each PI. L6 cells were serum deprived overnight and then exposed to $67 \mathrm{nM}$ insulin for $60 \mathrm{~min}$ prior to determination of 2-DG transport. All data \pm S.E.M.

\begin{tabular}{|c|c|c|}
\hline & Basal & With insulin \\
\hline \multicolumn{3}{|l|}{ Treatment } \\
\hline Control & $0 \cdot 338 \pm 0 \cdot 058$ & $0.733 \pm 0 \cdot 117^{2}$ \\
\hline Saquinavir & $0 \cdot 705 \pm 0.132^{b}$ & $1 \cdot 132 \pm 0 \cdot 147^{2}$ \\
\hline Indinavir & $0 \cdot 617 \pm 0 \cdot 08^{b}$ & $1 \cdot 17 \pm 0 \cdot 294$ \\
\hline Ritonavir & $0 \cdot 441 \pm 0 \cdot 1^{\mathrm{b}}$ & $0 \cdot 765 \pm 0 \cdot 132^{2}$ \\
\hline Amprenavir & $0 \cdot 76 \pm 0 \cdot 17^{b}$ & $1 \cdot 12 \pm 0 \cdot 22^{\mathrm{a}}$ \\
\hline
\end{tabular}

saquinavir or ritonavir on 2-DG transport in L6 cells (Table 1). In all cases, the PI treatment resulted in increased basal 2-DG transport. In subsequent studies, we have observed that insulin-stimulation of 2-DG transport was not decreased with any PI employed (Table 2). Basal 2-DG transport was significantly elevated in all PIexposed groups $(P<0 \cdot 05$, one-way ANOVA, $n=4$ triplicate determinations in all experiments). The average insulin to control ratios for no PI was $2 \cdot 16 \pm 0 \cdot 06$; for saquinavir-exposed, $1.62 \pm 0.08$; for indinavirexposed, $1.9 \pm 0.07$; for ritonavir-exposed, $1.73 \pm 0.09$; and for amprenavir-exposed 1·47 $\pm 1 \cdot 0$. 2-DG transport in all insulin-exposed groups was significantly different from basal $(P<0 \cdot 05$, one-way ANOVA, $n=4)$.

To determine the mechanism(s) of the 2-DG transport increase in the L6 cells (Fig. 2D), we examined the translocation of the GLUT 1, 3 and 4 into the plasma membrane fraction of L6 cells in the presence and absence of $67 \mathrm{nM}$ insulin and/or $10 \mu \mathrm{M}$ ritonavir (Fig. 2A-C). In Fig. 2A, Western blots of the plasma membrane fraction for GLUT 1 showed the increase in GLUT 1 into the plasma membrane of insulin-, ritonavir-, and ritonavir and insulin-exposed cells. In short, insulin induced an average 1.5-fold increase in 2-DG transport (Fig. 2D). In the presence of $10 \mu \mathrm{M}$ ritonavir, a nearly 2 -fold increase in 2-DG transport was observed (Fig. 2D), while increases in band density were observed for the GLUT 1, GLUT 3 (Fig. 2B) or GLUT 4 (the lowest being GLUT 4)

Figure 2 The effect of insulin, ritonavir and insulin plus ritonavir on 2-DG transport and glucose transporter translocation into a plasma membrane fraction derived from L6 cells. Details as in Materials and Methods. (A) An example of a Western blot probing for GLUT 1. The groups probed were no insulin control, $+67 \mathrm{nM}$ insulin (+Ins) or $10 \mu \mathrm{M}$ ritonavir (Rit) and insulin and ritonavir (Rit+Ins). One-way ANOVA, $n=5$. Data \pm S.E.M. ${ }^{*} P<0 \cdot 05$. (B) An example of a Western blot probing for GLUT 3. The groups were as described in (A). One-way ANOVA, $n=5$ or 6 . Data \pm S.E.M. ${ }^{*} P<0 \cdot 05$. (C) An example of Western blot probing for GLUT 4 . The groups were as described in (A). One-way ANOVA, $n=5$ or 6. Data \pm S.E.M. ${ }^{*} P<0 \cdot 05$. (D) The effects of the groups employed on 2-DG transport. One-way ANOVA, $n=8$, triplicate plates in all experiments. Data \pm S.E.M. ${ }^{*} P<0 \cdot 05$. 
A
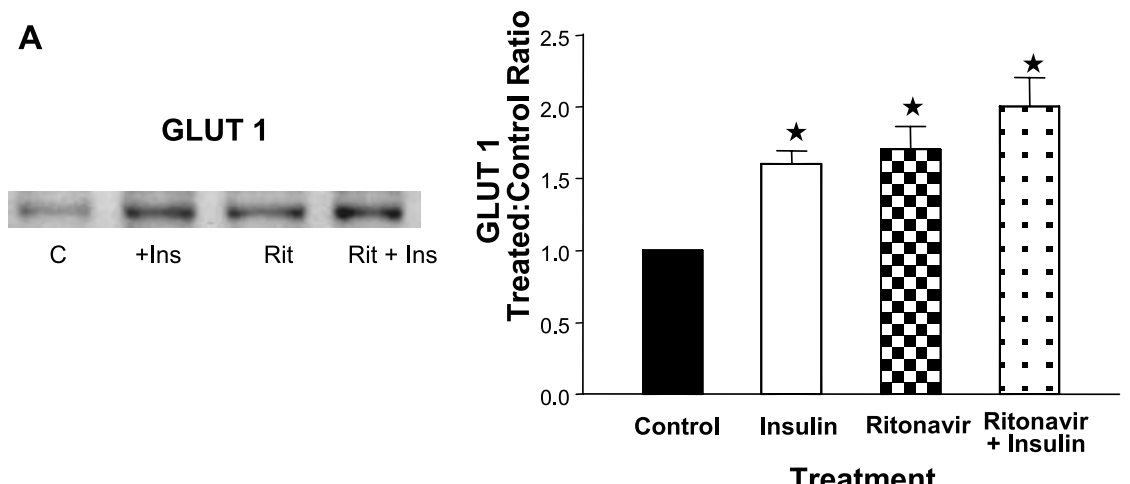

B

GLUT 3
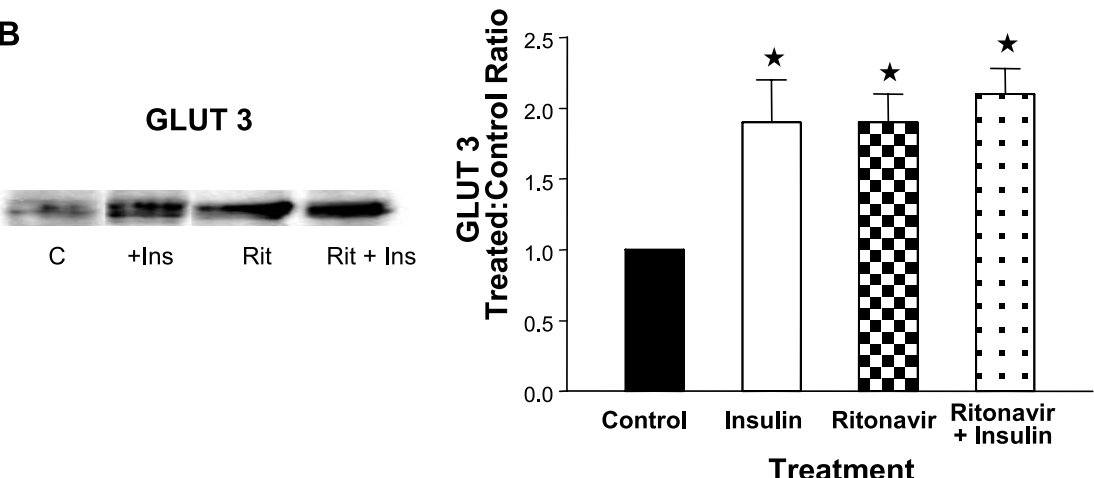

C
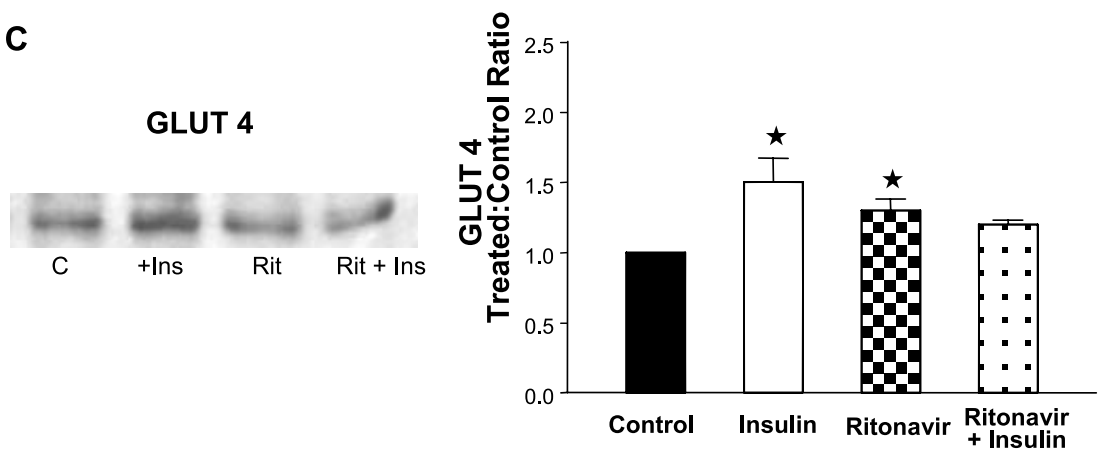

Treatment

D

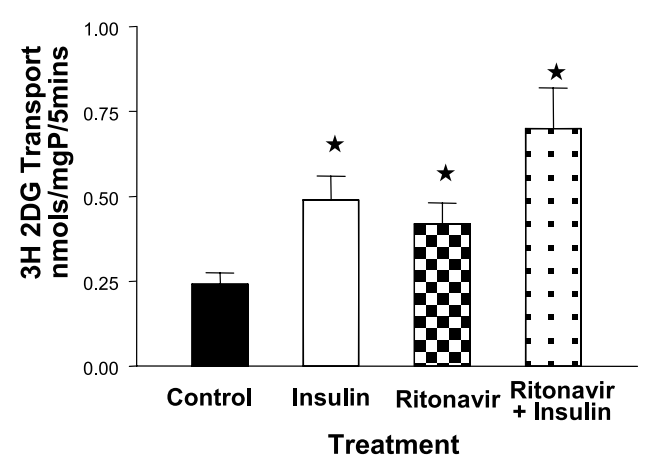


(Fig. 2C). This was seen for the plasma membranes of the GLUT 4 ritonavir plus insulin group. This was suggestive of some effect on the insulin group vs the insulin plus ritonavir group, although the differences were not significant $(P>0 \cdot 05$, one-way ANOVA). Regarding the magnitude of the changes seen in 2-DG transport, a number of studies showing the same magnitude of changes in 2-DG transport have demonstrated differences in band densities for GLUT 1, 3 and 4 (Andrejchyshyn et al. 1991, Germinario et al. 1993, Pratt \& Germinario 1994, Pratt et al. 1994, Tao et al. 1995). In PI-treated cells (i.e. ritonavir or indinavir) no differences in whole-cell transporter content (i.e. for the GLUT 1, 3 and 4) were observed (data not shown).

\section{Discussion}

The data presented herein indicate that long-term PIs have a considerable effect on 2-DG transport in L6 cells. The increased 2-DG transport rates were seen over a range of concentrations including physiological levels, i.e. known to occur in vivo $(1-10 \mu \mathrm{M})$. Further, the myotube system in the presence of insulin exhibited increased 2-DG transport in vitro. The L6 myotube system is a muscle-like cell line and hence it is a reflection of effects of PIs on muscle. The 3T3-L1 adipocyte reflects the fat cell and does not dispose of large amounts of glucose in vivo as the muscle does. The 3T3-L1 adipocyte, however, did not exhibit increased insulin-stimulated 2-DG transport after short-term exposure to PI and showed decreased basal 2-DG transport (Murata et al. 2000). Controversy does exist as others (Ranganathan \& Kern 2002) have shown increased basal 2-DG transport in 3T3-L1 adipocytes in the presence of indinavir and saquinavir. Also, they showed little or no effect of PI on insulin-stimulated 2-DG transport. An important consideration here is that the 2-DG uptake medium employed in our study lacked of the presence of PI. Further the PI effect on 2-DG transport is readily reversible (Nolte et al. 2001, Hruz et al. 2002). It must be noted that on 3T3-L1 cells, the conditions used in the cited study (Murata et al. 2000) employed considerably higher PI concentrations (20$100 \mu \mathrm{M})$ that those employed herein on L6 cells (1$10 \mu \mathrm{M})$, and more importantly shorter exposure times (6 min to $4 \mathrm{~h}$ vs $6-8$ days in the present study). It is of interest that the increased 2-DG transport seen in L6 cells is different from in vitro studies on muscle contraction (Nolte et al. 2001) and PI-induced decreases on muscle uptake (Nolte et al. 2001, Hruz et al. 2002). In the latter studies cited, PI exposure times again were short $(<2 \mathrm{~h}$ to $4 \mathrm{~h}$ ) and readily reversible. In our studies PI exposure was for several days during muscle differentiation at physiological concentrations of PI so the results are not directly comparable. This is indicative of another mechanism being involved. In the former studies indinavir appears to be interacting with the transporter directly negatively affecting GLUT 4 intrinsic activity. In our study, long-term exposure to PI did not affect glucose transport intrinsic activity (Joost et al. 1986, Calderhead \& Lienhard 1988, Clancey \& Czech 1990, Clancey et al. 1991, Harrison et al. 1991, Germinario et al. 1992, Pratt et al. 1994, Murata et al. 2000, Pessin \& Saltiel 2000) perhaps related to the lack of reversibility of the PI effect. Some factors have been shown to increase intrinsic activity (Joost et al. 1986, Calderhead \& Lienhard 1988, Clancey \& Czech 1990, Clancey et al. 1991, Harrison et al. 1991, Germinario et al. 1992) while others decrease the intrinsic activity of GLUTs (e.g. GLUT 4) (Pratt et al. 1994, Murata et al. 2000). Included in the latter group are PI effects in 3T3-L1 adipocytes (Murata et al. 2000).

Interestingly, we show increased 2-DG transport with changes in membrane-located GLUTs in L6 cells after PI exposure. One could speculate that other factors increase 2-DG transport (Hayashi 2000). For example, the increase might be indicative of PI-induced metabolic stress, which can lead to increased 2-DG transport. We have examined this and we have found no differences in total cellular GLUT 1 (an indicator of metabolic stress) (Hayashi et al. 2000), GLUT 3 or GLUT 4 in the presence or absence of ritonavir or indinavir (data not shown). Thus, this stressassociated gene (i.e. glucose transport) is not affected (Hayashi et al. 2000). Additionally, the L6 myotube is resistant to apoptosis as PI exposure and high concentrations of actinomycin D do not induce apoptosis in myotubes, using activation of caspase 3 as an indicator of such (data not shown). It is entirely possible that other intracellular signaling molecules are perturbed after exposure to PIs. Some investigators have demonstrated no effects on insulin receptor substrate-1, phosphatidylinositol 3-kinase or protein kinase B (PKB) (Murata et al. 2000) in 3T3-L1 adipocytes after PI treatment. Others have shown that nelfinavir decreases PKB phosphorylation by insulin (Rudich et al. 2001). To date no studies have been done with long-term PI in muscle in vitro either in the basal state or after insulin stimulation. The experimental protocols of the preceding study (Murata et al. 2000) were quite short-term compared with ours (e.g. $6 \mathrm{~min}$ to $4 \mathrm{~h}$ exposure vs 6 days in our study) and the PI was present in the uptake medium. Regarding the non-reversibility of PIinduced sugar transport, the possible involvement of transport regulatory proteins such as the atypical PKCs $(\alpha, \beta, \zeta)$ in this system are of considerable interest (Bandyopadhyay et al. 1997, Standaert et al. 1999). Recently, several investigators have indicated the involvement of PKB in insulin resistance and diabetic complications (Ishii et al. 1996, Bossenmaier et al. 1997). The results observed herein indicated that 2-DG transport is increased by continual exposure to PI in L6 cells. Interestingly, PKC $\beta_{1}$ knockout mice have increased basal sugar transport, which led the investigators to conclude that this form of PKC may be a negative regulator of sugar 
transport (Standaert et al. 1999). It may be that PKC $\beta_{1}$ is affected by PI, which would affect basal sugar transport. The complexities of sugar transport regulation are well established and the involvement of the atypical PKCs (Ishii et al. 1996, Banyopadhyay et al. 1997, Bossenmaier et al. 1997, Standaert et al. 1999) in basal sugar transport and insulin-stimulated sugar transport leads to possible multiple sites of interaction of the PI. At this point, we do not know what specific mechanism(s) is involved.

In summary, PIs resulted in increased 2-DG transport in L6 cells, which was not readily reversed after PI removal. Further, insulin-stimulated 2-DG transport was not decreased by long-term PI exposure in L6 cells (PI reversibility). Finally, in L6 cells, insulin- or ritonavir-induced increases in 2-DG transport did appear to involve the translocation of either GLUT 1, 3 or 4.

\section{Acknowledgement}

This work was supported in part by a grant from CANFAR.

\section{References}

Andrejchysyhn S, Continelli L \& Germinario RJ 1991 Permanent hexose transport upregulation in a respiration deficient human fibroblast cell strain. American Journal of Physiology 30 C973-C979.

Baldwin SA, Baldwin JM \& Leinhard GE 1982 Monosaccharide transporter of the human erythrocyte: characterization of an improved preparation. Biochemistry 21 3836-3842.

Bandyopadhyay G, Standaert ML, Galloway L, Moscat J \& Farese RV 1997 Evidence for the involvement of protein kinase C (PKC)- $\zeta$ and non involvement of diacylglycerol-sensitive PKC's in insulinstimulated glucose transport in L6 cells. Endocrinology $\mathbf{1 3 8}$ $4721-4731$.

Baron AD, Steinberg H, Brechtel G \& Johnson A 1994 Skeletal muscle blood flow independently modulates insulin-mediated glucose uptake. American Journal of Physiology 266 E248-E253.

Bilan P, Mitsumoto Y, Maher F, Simpson I \& Klip A 1992 Detection of the GLUT3 facilitative glucose transporter in rat L6 muscle cells: regulation by cellular differentiation, insulin and insulin-like growth factor I. Biochemical and Biophysical Research Communications 186 1129-1137.

Bossenmaier B, Mosthaf L, Mischak H, Ullrich A \& Haring HU 1997 Protein kinase $C$ isoforms $\beta_{1}$ and $\beta_{2}$ inhibit tyrosine kinase activity on the insulin receptor. Diabetologia 40 863-866.

Calderhead DM \& Leinhard GE 1988 Labelling of the glucose transporters at the cell surface in 3T3-L1 adipocytes. Journal of Biological Chemistry 263 12171-12174.

Carr A, Samaras K, Burton S, Law M. Freund J, Chisholm DJ \& Cooper DA 1998 A syndrome of peripheral lipodystrophy, hyperlipidaemia and insulin resistance in patients receiving HIV protease inhibitors. AIDS 12 F51-F58.

Carr A, Miller J, Law M \& Cooper D 2000 A syndrome of lipoatrophy, lactic acidaemia and liver dysfunction associated with HIV nucleoside analogue therapy: contribution to protease inhibitor-related lipodystrophy syndrome. AIDS 14 F25-F32.

Clancey BM \& Czech MP 1990 Hexose transport stimulation and membrane distribution of glucose transporter isoforms in response to cholera toxin, dibutyrl cyclic AMP and insulin in 3T3-L1 adipocytes. Journal of Biological Chemistry 265 12434-12443.
Clancey BM, Harrison SA, Buxton JM \& Czech MP 1991 Protein synthesis inhibitors glucose transport without increasing plasma membrane glucose transporters in 3T3-L1 adipocytes. Journal of Biological Chemistry 266 10122-10130.

DeFronzo RA, Jacot E, Maeder E, Wahren J \& Felber JP 1981 The effect of insulin on the disposal of intravenous glucose: results from indirect calorimetry and hepatic and femoral venous catheterization. Diabetes 20 1000-1007.

Flexner C 1998 HIV protease inhibitors. New England Journal of Medicine 338 1281-1292.

Gao WY, Shiraska T, Johns DG, Broder S \& Mitsuya H 1993 Differential phosphorylation of azidothymidine, dideoxythymidine and dideoxyinosine in resting and activated peripheral blood mononuclear cells. Journal of Clinical Investigation 91 2326-2333.

Germinario RJ, Oliveira M \& Leung L 1978 Saturable and nonsaturable hexose uptake in cultured human skin fibroblasts. Canadian Journal of Biochemistry 56 80-88.

Germinario RJ, Lakshmi TM \& Thirion JP 1989 Kinetic characteristics and regulation of hexose transport in a galactokinase negative Chinese hamster fibroblast cell line: a good model for studies on sugar transport in cultured mammalian cells. Journal of Cellular Physiology 138 300-304.

Germinario RJ, Manuel S, Chang Z \& Leckett B 1992 Inhibitors of protein synthesis cause increased hexose transport in cultured human fibroblasts by a mechanism other than transporter translocation. Journal of Cellular Physiology 151 156-163.

Germinario RJ, Sniderman AD, Manuel S, Pratt-Lefevre S, Baldo A \& Cianflone K 1993 Coordinate regulation of triacyglycerol synthesis and glucose transport by acylation stimulating protein. Metabolism 42 574-580.

Gervasoni C, Ridolpho AL, Trifiro G, Santambrogic S, Norbiato G, Musicco M, Clerici M, Galli M \& Moroni M 1999 Redistribution of fat in HIV-infected women undergoing combined antiretroviral therapy. AIDS 13 465-472.

Hammer SM, Squires KE, Hughes MD, Grimes JM, Derneter LM, Currier JS, Eron JJ, Feinberg JE, Balfour HH, Deyton LR et al. 1997 A controlled trial of two nucleoside analogues plus indinavir in persons with immunodeficiency virus infections and CD4 cell counts of 200 per cubic millimeter or less. New England Journal of Medicine 337 725-733.

Harrison SA, Buxton JM, Clancey BM \& Czech MP 1991 Evidence that erythroid-type glucose transporter intrinsic activity is modulated by cadmium treatment of mouse 3T3-L1 cells. Journal of Biological Chemistry 266 19438-19449.

Hayashi T, Hirshman, MF, Fujii N, Habinowski SA, Witters LE \& Goodyear L 2000 Metabolic stress and altered glucose transport. Diabetes 49 527-531.

Hruz P, Murata H, Qui H \& Mueckler M 2002 Indinavir induces acute and reversible peripheral insulin resistance in mice. Diabetes 51 937-942.

Ishii H, Jirousek MR, Koya D, Takagi C, Xia P, Clermont A, Bursell S, Kern TS, Ballas LM, Heath WF et al. 1996 Amelioration of vascular dysfunctions in diabetic rats by an oral PKC- $\beta$ inhibitor. Science 272 728-731.

Joost HG, Weber TM, Cushman SW \& Simpson IA 1986 Insulinstimulated glucose transport in rat adipose cells. Journal of Biological Chemistry 261 10033-10036.

Laemmli UK 1970 Cleavage of structural proteins during the assembly of the head of bacteriophage T4. Nature 227 680-685.

Lo JC, Mulligan K, Tai VW \& Alfren H 1998 'Buffalo hump' in men with HIV-1 infection. Lancet $351867-870$.

Lowry OH, Roseborough NJ, Farr J \& Randall RJ 1951 Protein measurements with the Folin phenol reagent. Journal of Biological Chemistry 193 265-275.

Martin JA, Redshaw S \& Thomas GT 1995 Inhibitors of HIV proteinase. Progress in Medicinal Chemistry 32 239-287.

Mouton Y, Alfandari S, Valette M, Cartier JK, Dellamonica P, Humbert G, Lang JM, Massip P, Mechali D, Leclercq P et al. 1997 
Impact of protease inhibitors on AIDS defining events and hospitalization in 10 French AIDS centers. AIDS 11 F101-F105.

Mulligan K, Grunfeld C, Tai VW, Algren H, Pang M, Chernoff DN, Lo JC \& Schambelan M 2000 Hyperlipidaemia and insulin resistance are induced by protease inhibitors independent of changes in body composition in patients with HIV infection. AIDS $\mathbf{2 3}$ 35-43.

Murata H, Hruz PW \& Mueckler M 2000 The mechanism of insulin resistance caused by HIV protease inhibitor therapy. Journal of Biological Chemistry 275 20251-20254.

Nolte AN, Yarasheshski KE, Kawanaka K, Fisher J, Le N \& Holloszy JO 2001 The HIV protease inhibitor indinavir decreases insulin and contraction-stimulated glucose transport in skeletal muscle. Diabetes 50 1397-1401.

Pessin JE \& Saltiel AR 2000 Signaling pathways in insulin action: molecular targeters of insulin resistance. Journal of Clinical Investigation 106 165-169.

Pratt S \& Germinario RJ 1994 Differential glycosylation of the glucose transporter coincides with enhanced sugar transport in respiration deficient cells. Biochemical and Biophysical Research Communications 200 1313-1320.

Pratt SE, Colby-Berminario SP, Manuel S \& Germinario RJ 1994 The mechanism of the $\mathrm{D}$-allose induced decrease in sugar transport does not involve transporter translocation. Journal of Cellular Physiology 161 580-588.

Ranganathan S \& Kern PA 2002 The HIV protease inhibitor saquinavir impairs lipid metabolism and glucose transport in cultured adipocytes. Journal of Endocrinology 172 155-162.
Reaven GM 1993 Role of insulin resistance in human disease (Syndrome X): an expanded definition. Annual Review of Medicine 44 121-133.

Reaven GM 1999 Syndrome X: 6 years later. Journal of International Medicine 736 (Suppl) 13-22.

Rudich A, Vanounou S, Risenberg K, Porat M, Tirosh A, Harmon-Boehm I, Greenberg AS, Schlaffer F \& Bashen N 2001 The HIV protease inhibitor nelfinavir induces insulin resistance and increases basal lipolysis in 3T3-L1 adipocytes. Diabetes $\mathbf{5 0}$ 1425-1431.

Standaert ML, Bandyopadhyay G, Galloway L, Soto J, Ono Y, Kikkawa U, Farese RV \& Leitges M 1999 Effects of knockout of the protein kinase $\mathrm{C}$ beta gene on glucose transport and glucose homeostasis Endocrinology 140 4470-4477.

Tao Y, Sniderman A, Cianflone K, Colby-Germinario SP \& Germinario RJ 1995 Acylation stimulating protein (ASP) regulates sugar transport in the rat L6 muscle cell line. Biochimica et Biophysica Acta 1334 221-229.

Virabin R \& Aquilina C 1998 Indinavir associated lipodystrophy. AIDS 12 F37-F39.

Winslow DL \& Otto MJ 1995 HIV protease inhibitors AIDS 9 (Suppl A) S183-S192.

Received in final form 27 May 2003

Accepted 29 May 2003 